Journal of International Students । 132

Peer-Reviewed Article

ISSN: 2162-3104 Print/ ISSN: 2166-3750 Online

Volume 5, Issue 1 (2015), pp. 132-142

(C) Journal of International Students

http://jistudents.org/

\title{
International Students' Enhanced Academic Performance: Effects of Campus Resources
}

\author{
Delphine N. Banjong (Doctoral Student) \\ Department of Teaching \& Learning \\ University of North Dakota (USA)
}

\begin{abstract}
This article investigates international students' challenges, such as financial, English proficiency, loneliness/homesickness in the United States. In addition, it assesses how these students coped with such difficulties by making use of resources on campus, such as an international center, writing center, counseling center, and the student success center. Based on 344 responses, the results indicated that international students with language difficulties sought help from the writing and student success centers while those who reported financial stress and loneliness had visited the counseling center.
\end{abstract}

Keywords: international students; academic performance; challenges; campus resources

International students constitute a good proportion of student population in universities and colleges in the United States (Open Doors Report, 2013). International student enrollment in U.S. colleges and universities has increased by $7 \%$, to a total of 819,644 , with most of the students contributing coming from China, India, South Korea, and Saudi Arabia (Open Doors, 2013). When international students move to foreign countries, they face challenges as they try to adjust to their new environments (Ward, Bochner, \& Furnham, 2001; Yeh \& Inose, 2003). Some of these challenges are anticipated while others are not foreseen. International students manage to cope with these problems as they shift from their cultural norms and adapt to the way of life in their new environments. Acculturation is often quite challenging, coupled with the fact that these students also face academic pressure. These difficulties tend to have negative consequences on these students' health and academic achievement (Kilinc \& Granello, 2003). Some of the prominent difficulties of international students include culture shock, homesickness, loss of social support, discrimination, language barriers, loneliness, depression, and anxiety (Faleel et al., 2012; McClure, 2007; Zhao et al., 2008), and these difficulties upset their academic performance.

A number of studies have looked at the experiences and challenges of international students (; Kuo, 2011; Lee, 2010; Tucker \& Ang, 2007), but a few studies have examined how these international students still succeed academically despite the odds (Tseng \& Newton, 2002).

Summer 2015

http://jistudents.org

Volume $5 \cdot$ Issue 2 
This study seeks to investigate the problems of international students at a university in the Midwest and assess how these students had been able to manage their difficulties partly by making use of campus resources.

International students experience difficulty adjusting to their new environments and new ways of life. Shih and Brown (2000) noted that international students generally faced more adjustment problems than did U.S. students, and that the top five adjustment problems were (1) lack of English proficiency, (2) inadequate financial resources, (3) problems in social adjustment or integration, (4) problems in daily living, and (5) loneliness or homesickness. Shih and Brown (2000), in concert with Wan et al. (1992), posited that these adjustment difficulties tended to affect international students' academic performance, mental and physical health, level of satisfaction with their cross-cultural experiences, and attitudes toward the host nations as they seek to adapt to their new environment. However, international students do not seek counseling like domestic students do (Misra \& Castillo, 2004) because some of them view the word counseling as a negative term (Onabule \& Boes, 2013), and they might not be familiar with the counseling process (Olivas \& Li, 2006). Nevertheless, Sherry, Thomas, and Chui (2010) showed that the writing center has been of great help to international students with the composition of their papers.

Shih and Brown (2000) defined acculturation as a dynamic process of relating to a dominant group by which a minority group selectively adopts its value system and cultural practices when involved in the processes of integrating with, and differentiating from, the dominant group and that such changes result in three possible outcomes. These outcomes include (a) assimilation wherein a person from a minority group replaces his/her own culture with the host culture's attitudes, values, and behaviors; (b) resistance to assimilation wherein a person from a minority group clings to his/her own culture and resists the host country's culture (Suinn et al., 1995); and (c) biculturalism wherein a person from a minority culture adopts aspects from both his/her own culture and the host culture; (Suinn et al., 1995). While Suinn uses the term biculturalism, Gibson (1998) uses the term accommodation and acculturation without assimilation to explain that the student retains his/her home culture but learns and participates in the culture of the host countries, thereby, blending the two cultures to facilitate their adaptation. The type of culture these students adopt determines the magnitude of stress they experience.

The acculturative stressors encountered by international students have been known to lead to mental and psychological illnesses, such as depression and anxiety. Some scholars such as Parr, Bradley, and Bingi (1992) believe that international students are a resilient group, but many studies have shown that the challenges faced by these students, particularly in the early stages of their stay in the United States as they adjust to their new educational and social environment (Sherry et al., 2010).

The stressors experienced by international students in U. S. colleges and universities have resulted in conflicts between the students and faculty supervisors in some instances. International student-supervisor conflicts have been found to result from international students' lack of English proficiency, unclear expectations, lack of openness, time, and feedback (Adrian-Taylor, Noels, \& Tischler, 2007). However, the advisors know that international students are hardworking (Nguyen, 2013). Research has found that host nation students generally seek help from their supervisors only on academic or vocational problems but turn to friends or other sources for help on emotional and other personal problems (Leong \& Sedlacek, 1986). This seeking of help is not the same with international students who look up to their supervisors for almost everything, given that they are generally unfamiliar with their new society. Unfortunately, 
due to cultural disparities, international students often find it difficult at the initial stages to get along with some supervisors (Adrian-Taylor et al., 2007) and understanding coursework. Many of these students possess an accent that makes it difficult for some American professors to understand them when they speak, and students themselves have difficulties hearing the professors' accent when they just come into the United States (Kuo, 2011), and this affects their level of communication.

The purpose of the present work was to investigate the problems of international students in a U.S. Midwestern University and to assess how these students have been able to manage their difficulties, partly by making use of campus resources, such as the international center, student success center, counseling center, and the writing center. This study seeks to answer the following questions: 1) Did international students at the target university face challenges? Did such challenges adversely affect their school performance? 2) How useful are campus resources to this group of students?

\section{Participants}

\section{Method}

At the time when this study was carried out, the university had a total international student population of 1,077 (Undergraduate students numbered 694, graduate students numbered 263 , and dependents of students defined as either spouses or children of international students numbered 120). The respondents to the study were 349 international students enrolled at the university, resulting in a response rate of $36.5 \%$. The gender of the respondents were 198 male and 146 female. The respondents were from four different continents: North America, including Belize, Canada, Grenada, and Jamaica $(n=45)$; Asia, including China, Taiwan, Korea, India, Nepal, Pakistan, Saudi Arabia, Sri Lanka, Thailand, Philippines, Iran, Japan, and Bangladesh ( $n$ = 172); Europe, including France, England, Germany, Norway, UK, Ukraine, Czech Rep. Croatia, and Albania $(n=38)$; and Africa, including Egypt, Cameroon, Kenya, Zambia, Togo, Nigeria, Liberia, Ghana, Eritrea, and Tanzania $(n=89)$.

\section{Instrument}

The author designed the questionnaire for this study consisting of three parts: (1) demographics, (2) students' needs/problems, and (3) campus facilities. Questions on demographics covered information about the age, gender, country of origin, educational level, length of stay in the United States, funding sources for students, and visa status. Questions under students' needs and/or problems focused on financial crises, English proficiency, and loneliness/homesickness. Questions on campus facilities investigated the students' level of interaction and assistance they have had from the international center, writing center, student success center, and counseling center at the university. One dependent variable question was asked to assess the academic success level of international students. Students responded to all questions, except those on demographics, on a five-point Likert scale $(1=$ strongly disagree to 5 = strongly agree). The descriptive statistics on these scales are displayed in the appendix section.

In order to assess the effects of the lack of English proficiency, loneliness/homesickness, and the financial life of international students on their academic performance, a factor analysis was conducted with these three different scales. Varimax rotation was used to determine the distinct constructs into meaningful and comparable measures. The validity of the data obtained 
was determined using an exploratory factor analysis. Internal reliability was found to be sufficient for all of the scales, $(\alpha=.69-.89)$, and the scale distributions all approached normality (that is, skewness and kurtosis less than or equal to +1.00 ). From the factor analysis, a fourth factor emerged, which the researcher labeled "technology." Some items on the scales were removed due to negative, weak, or cross loadings on other factors. In the end, there were four factors, which will be used for further analysis in this study. These factors were (1) lack of English proficiency, (2) loneliness/homesickness, (3) financial life, and (4) technology. The dependent variable in this study was students' academic success and the following question was asked, "How successful do you feel you are in your studies?" Students responded on a 5-point Likert scale from 1 "very unsuccessful" to 5 "very successful." Students spent an average of 8.6 minutes to complete the survey. Usable responses total 344 while five (5) were incomplete and, thus, rejected.

\section{Procedure}

In the beginning of Fall 2013, an online survey/questionnaire was designed by the author and sent to all international students, except for their dependents, to be completed at the U.S. Midwestern University where the study was conducted. The survey was sent to the students through the International Center and re-sent after one week, so that the survey remained open for a total of two weeks. Participants were asked to respond based on how they felt about each statement. A total of 344 students had completed the questionnaire. Students were encouraged to complete the survey but no additional incentive was given to participants.

\section{Results}

A Pearson product-moment correlation coefficient was computed to assess the relationship between the challenges of international students and their academic success. English proficiency had a significant negative correlation value of $(r(325)=-.46, p<.001)$ in relation to academic success. These students were the most negatively affected with regards to school outcomes. Loneliness and homesickness had a significant negative correlation with academic success of $(r$ $(321)=-.325, p<.001)$. This result suggests that students who lived in solitude, or who had little social interaction, and felt depressed (as a consequence of homesickness) tended not to focus on their studies. This was then reflected in their poor school outcomes.

Table 1

Correlations among Students' Academic Success and their Challenges

\begin{tabular}{|c|c|c|c|c|c|c|}
\hline & 1 & 2 & 3 & 4 & 5 & $\alpha$ \\
\hline 1. Academic Success & - & $-.46^{* * *}$ & $-.33^{* *}$ & $-.24^{* * *}$ & $-.13^{*}$ & - \\
\hline 2. English Proficiency & & - & $.59^{* *}$ & $.44^{* *}$ & $.53^{* *}$ & .895 \\
\hline 3. Loneliness and Home Sickness & & & - & $.20^{* *}$ & $.39^{* *}$ & .895 \\
\hline 4. Finance & & & & - & $.40^{* *}$ & .717 \\
\hline 5. Technology & & & & & - & 611 \\
\hline
\end{tabular}
Note. $p<.05 ;{ }^{* *} p<.001$.

The third obstacle of international students was financial needs. A significant negative correlation of $(r(332)=-.24, p<.001)$ was found between financial needs and academic 
achievement. Technological challenges had a correlation value of only $(r(321)=-.13 p<.05)$. There was a significant negative correlation between stressors experienced by foreign students and their academic performance (see Table 1).

Students who reported English language difficulties were largely found to have visited the writing and success centers to seek help with homework. Such visits positively impacted the academic outcome of international students. Visits to the writing center gave a significant positive correlation of $(r(325)=.371, p<.001)$ in relation to academic performance, while visits to the success center gave a correlation value of $(r(320)=.268 p<.001)$ with respect to academic achievement. Students who reported having felt lonely and homesick in their new environment were found to have visited the counseling center. These visits had a positive effect on their school outcome, giving a significant correlation value of $(r(331)=.15, p<.001)$. Financially needy students were also reported to have sought counseling. A significant correlation of $(r$ $(332)=-.141, p<.001)$ with respect to school outcome was found in this regard. In general, International Students with challenges sought help around campus in one way or another. Campus facilities proved resourceful and helpful to international students, improving their academic performance.

Next, the success level of international students had significantly negative correlation with campus facilities. Students who felt least successful in their courses appeared to have visited the success center the most, giving a negative correlation value of $(r(329)=-.43$, $p<.001)$. Counseling service center was negatively correlated with the academic success of international students $(r(334)=-.372, p<.001)($ see Table 2$)$.

Table 2

Correlations among Students' Academic Success and Campus Facilities

\begin{tabular}{llccccc}
\hline & & 1 & 2 & 3 & 4 & 5 \\
\hline 1. & Academic Success & - & -.03 &.$- .23^{* *}$ & $-.43^{* *}$ & $-.37^{* *}$ \\
2. International Center & & - & $.40^{* *}$ & $.29^{* *}$ & .08 \\
3. Writing Center & & & - & $.55^{* *}$ & .08 \\
4. & Student Success & & & & - & $.27^{* *}$ \\
& Center & & & & - \\
5. & Counseling Center & & & & - \\
\hline
\end{tabular}

Note. ${ }^{*} p<.05 ;{ }^{* *} p<.001$.

Lastly, a negative correlation with respect to school success of $(r(334)=-.232, p<.001)$ was found for low performing international students who sought help from the writing center. Visits to the international center did not show any correlation with the challenges of international students. The correlation coefficients in this case were insignificant, which means that virtually all international students visit the international center irrespective of whether they are stressed or not. Comparing the writing center to the international center, a positive significant correlation coefficient of $(r(334)=.397, p<.001)$ was found, implying that students who visited the writing center also visited the international center (see Table 2).

A multiple linear regression analysis was performed to investigate how challenges of international students predicted their future academic performance. A significant regression equation was found $(F(4,298)=25.212, P<.001)$, with an $R^{2}$ value of $26 \%$. This result implied that $26 \%$ of the failure of international students resulted from the problems they faced or that the 
removal of these challenges could improve the academic outcome of international students by at least $26 \%$.

The role of campus resources in predicting the academic outcome of international students was also probed through multiple linear regression analysis. A significant regression equation was found $(F(4,326)=30.187, P<.001)$, with an $R^{2}$ value of $27 \%$. These results showed that if international students were encouraged to pay visits to the different centers on campus to seek help, their school performance could improve by at least $27 \%$. In general, the different campus resources proved to be resourceful to international students and motivating students to visit these centers would improve international students' life and performance.

\section{Discussion}

International students faced various challenges, with English proficiency being the most challenging for this set of students. The academic performance of international students could greatly improve if they seek help from campus resources concerning the challenges they face.

Lack of English proficiency is a major problem faced by international students, which is not surprising since without proficiency in a language of instruction, students are neither able to fully follow lectures and understand notes from such lectures, nor write assessment tests and exams properly. Kuo (2011) found that graduate international students could not understand class lectures because of the speed with which the professors lectured coupled with their accents. Lack of English proficiency has widely been reported in the literature as a key obstacle to international students. For example, Shih and Brown (2000), as well as Zhai (2002), observed that a deficiency in the English language topped the list of problems of international students. While investigating adjustment problems of international students, Gebhard (2012) found that some international students could not even express themselves clearly in English during the participants' interviews.

In the current study, a strong positive correlation was found between English language barriers and visitation to the writing and student success centers on the campus involved in the study. Students who reported difficulties with English language were found to have visited these centers, and such visits apparently impacted their school outcome positively. Sherry et al., (2010) also found the Writing and American Language Centers particularly helpful to international students with language difficulties. With the lack of English proficiency, making new friends can be difficult; international students are likely to develop a complex and such forces will play into their academic success.

Loneliness/homesickness constituted the next level of crises faced by international students in this study. This study found loneliness and homesickness to adversely impact the academic output of these students. Telbis et al. (2014) showed that students who had high confidence in their community acceptance also displayed proportionate confidence in the completion of their programs of study. It seems plausible that loneliness leads to stress and depression, and results from the inability of foreign students to immediately blend into a new society and meet up with their studies. Language barriers are among the crises that breed timidity, fear, and isolation among international students. Such isolation often degenerates to depression, which, in turn, affects academic achievement.

Loneliness and homesickness often decrease among international students the longer they stay in their new environment (Sawir et al., 2008). Building new social networks is often a challenge to these students, particularly when the language barrier is present. However, 
international students who make friends with students of other nationalities are often found to be happier, more fulfilled, and less homesick (Hendrickson, Rosen, \& Aune, 2011). Counseling centers on campuses have been reported to improve international students' ordeal of loneliness but are generally less utilized by these students in comparison to domestic students (Misra \& Castillo, 2004). In this present study, students who felt lonely went to the counseling center to seek help. Onabule and Boes (2013) observed that some international students perceived the counseling center negatively, which seems to suggest that such students felt that only students with special disabilities or problems needed to go there for counseling. Consequently, such students did not feel needful enough to have visited the center.

Financial pressure adversely impacts international students' level of school performance and moderates their decisions to quit school or persevere in their studies (Bennett, 2003). Financial pressure on international students owes its explanation to the fact that such students generally are required to pay more tuition than domestic students, and exchange rates may be unfavorable to them such that a small amount of money in the currency of their host country is equivalent to a large sum of money in their home country (Geo, 2008). In the present study, students who had financial crises had poor academic performance. These students, because they could not handle the stress associated with the lack of finance, ended up going to the counseling center to seek help.

The next reported obstacle to international students in this study was technology. Encountering new advanced technology can be a nightmare and demoralizing when a person is unable to find a way around accommodating themselves to the technology. International students from developing countries, in particular, frequently encounter new unfamiliar technology when they travel to study in western countries. In this study, some of these students were unable to type well, use blackboard on school websites to interact with course professors, download course material, or do homework. Such challenges often lead to frustration and poor academic performance.

\section{Limitations and Future Directions}

A limitation of this study was the fact that only one campus was involved. The study generalized international students from all cultures and did not consider the fact that these students had different backgrounds and hence might solve challenges in different ways. Neither did the study consider the fact that undergraduate or graduate students could face different challenges. Future studies should consider more universities to ensure that the results would not be campus-specific and void of diversity from a variety of campuses. Also, research should be carried out to determine if international students from different cultures and the different academic levels (e.g., first year, second year, etc.) face different challenges and how they go about solving those challenges. A mixed-method study could also be considered, which would present an opportunity to explore both quantitative and qualitative data, allowing for a more in-depth discovery of patterns, practices, and the traditions of international students, which was beyond the scope of the current study.

\section{Implications}

This study reveals the importance of campus resources to international students, and so, they should be encouraged to visit these centers for help. More awareness about the location and functioning of these centers needs to be done since some students indicated that they did not 
know where to find help on campus. International centers should reinforce their efforts of sensitizing the international students about the resources on campus. Sensitization of international students is very important especially on their arrival. If these students know about the campus resources early, this information will help then to adapt easily and reduce challenges thereby improving their school performance.

New international students are suggested to be paired with other international students who are mentors on campus who have already been in the U.S. for at least a year. The student who has been in the U.S. should know about the resources on campus and have received help from them. Pairing these sets of international students will ease adaption for the new student because the mentors have been in the U.S. for a while, and they will be able to direct the new students to campus resources where they can seek help. This knowledge will help the new student reduce challenges and more easily adapt to the system and, hence, improve in their academic performance.

\section{REFERENCES}

Adrian-Taylor, S. R., Noels, K. A., \& Tischler, K. (2007). Conflict between international graduate students and faculty supervisors: Toward effective conflict prevention and management strategies. Journal of Studies in International Education, 11(1), 90-117. doi:10.1177/1028315306286313

Anderson, S. (2010). Debunking myths about international students and highly skilled immigrants. International Educator, 19(5). 4-7.

Bennett, R. (2003). Determinants of undergraduate student dropout rates in a university business studies department. Journal of Further and Higher Education, 27(2), 123-141.

Christie, H., Munro, M., \& Fisher, T. (2004). Leaving university early: Exploring the differences between continuing and non-continuing students. Studies in Higher Education, 29(5), 617-636.

Faleel, S. F, Tam, C. L, Lee, T. H, Har, W. M., \& Foo, Y. C. (2012). Stress, perceived social support, coping capability and depression: A study of local and foreign students in the Malaysian context. International Journal of Social and Human Sciences, 6, 8-14.

Gebhard, J.G. (2012) International students' adjustment problems and behaviors. Journal of International Students, 2(2), 184-193.

Geo, F. (2008). Financial pressure. International students in the U.S. Retrieved from: http://plaza.ufl.edu/ffgao/mmc5015/final/financial.html

Gibson, M. A. (1988). Accommodation without assimilation: Sikh immigrants in an American high school. Ithaca, NY: Cornell University Press.

Goodman, A. E., \& Blumenthal, P. (2013). Open Doors 2013: International students in the United States and study abroad by American students are at all-time High. Institute of International Education. Retrieved from http://www.iie.org/Who-We-Are/News-andEvents/Press-Center/Press-Releases/2013/2013-11-11-Open-Doors-Data\#.Uq9fjhx0uZg

Hendrickson, B., Rosen, D., \& Aune, R. K. (2011). An analysis of friendship networks, social connectedness, homesickness, and satisfaction levels of international students. International Journal of Intercultural Relations, 35(3), 281-295. doi:10.1016/j.ijintrel.2010.08.001

Institute of International Education. (2013). International Student Enrollment Trends, 1949/502011/13. Open Doors Report on International Educational Exchange. 
Retrieved from http://www.iie.org/opendoors

Institute of International Education. (2012). Special Reports: Economic impact of international students. Open Doors Report on International Educational Exchange. Retrieved from http://www.iie.org/Research-and-Publications/Open-Doors/Data/Economic-Impact-ofInternational-Students

Kilinc, A., \& Granello, P. F. (2003). Overall life satisfaction and help-seeking attitudes of Turkish college students in the United States: Implications for college counselors. Journal of College Counseling, 9, 56-68.

Kuo, Y. H. (2011). Language challenges faced by international graduate students in the United States. Journal of International Students, 1(2), 38-42.

Lee, J. J. (2010). International students' experiences and attitudes at a US host institution: Selfreports and future recommendations. Journal of Research in International Education, 9(1), 66-84. doi:10.1177/1475240909356382

Leong, F. T., \& Sedlacek,W. E. (1986). A comparison of international and U.S. students' preferences for help sources. Journal of College Student Personnel, 27, 426430.

McClure, J. W. (2007). International graduates' cross-cultural adjustment: Experiences, coping strategies, and suggested programmatic responses. Teaching in Higher Education, 12(2), 199-217. doi:10.1080/13562510701191976

Misra, R., \& Castillo, L. G. (2004). Academic stress among college students: Comparison of American and international students. International Journal of Stress Management, 11, 132-148. doi:10.1037/1072-5245.11.2.132

Neri, F., \& Ville, S. (2008). Social capital renewal and the academic performance of international students in Australia. The Journal of Socio-Economics, 37, 1515-1538. doi:10.1016/j.socec.2007.03.010

Nguyen, M. H. (2013). Faculty advisors' experiences with international graduate students. Journal of international Students, 3(2), 102-116,

Olivas, M., \& Li, C. (2006). Understanding stressors of international students in higher education: What college counselors and personnel need to know. Journal of Instructional Psychology, 33(3), 217-222.

Onabule, A. I., \& Boes, S. R. (2013), International students' likelihood to seek counseling while studying abroad. Journal of International Students, 2(1), 52-59.

Parr, G., Bradley, L., \& Bingi, R. (1992). Concerns and feelings of international students. Journal of College Student Development, 33(1), 20-25.

Reynolds, A. L \& Constantine, M. G. (2007). Cultural adjustment difficulties and career development of international college students. Journal of Career Assessment, 15, 338350. doi:10.1177/1069072707301218

Rienties, B., Beausaert, S., Grohnert, T., Niemantsverdriet, S., \& Kommers, P. (2012). Understanding academic performance of international students: the role of ethnicity, academic and social integration. Higher Education, 63(6), 685-700.

Sawir, E., Marginson, S., Deumert, A., Nyland, C., \& Ramia, G. (2008). Loneliness and international students: An Australian study. Journal of Studies in International Education, 12(2), 148-180. doi:10.1177/1028315307299699

Sherry, M., Thomas, P., \& Chui, W. H. (2010). International students: A vulnerable student population. Higher Education, 60(1), 33-46. 
Shih, S, \& Brown, C. (2000). Taiwanese international students: Acculturation level and vocational identity. Journal of Career Development, 27, 35-47.

Suinn, R. M., Khoo, G., \& Ahuna, C. (1995). The Suinn-Lew Asian self-identity acculturation scale: Cross-Cultural information. Journal of Multicultural Counseling and Development, 23(3), 139-148. doi:10.1002/j.2161-1912.1995.tb00269.x

Telbis, N. M., Helgeson, L., \& Kingsbury, C. (2014). International Students' Confidence and Academic Success. Journal of International Students, 4(4), 330-341.

Trice, A. G. (2003). Faculty perceptions of graduate international students: The benefits and challenges. Journal of Studies in International Education, 7(4), 379-403. doi:10.1177/1028315303257120

Tseng, W. C., \& Newton, F. B. (2002). International students' strategies for well-being. College Student Journal, 36(4), 597-598.

Tucker, R., \& Ang, S. (2007). The academic acclimatization difficulties of international students of the built environment. Emirates Journal for Engineering Research, 12(1), 19.

Wan, T. Y., Chapman, D. W., \& Biggs, D. A. (1992). Academic stress of international students attending US universities. Research in Higher Education, 33(5), 607-623.

Ward, C. A., Bochner, S., \& Furnham, A. F. (2001). The psychology of culture shock. East Sussex, UK: Routledge.

Weiss, R. S. (1973). Loneliness: The experience of emotional and social isolation. Cambridge, MA: MIT press.

Yeh, C. J., \& Inose, M. (2003). International students' reported English fluency, social support satisfaction, and social connectedness as predictors of acculturative stress. Counselling Psychology Quarterly, 16(1), 15-28. doi:10.1080/0951507031000114058

Zhai, L. (2002). Studying international students: Adjustment issues and social support. San Diego, CA: Office of Institutional Research San Diego Community College District.(ERIC Document Reproduction Service No. ED 474481).

Zhao, Y., Jindal-Snape, D., Topping, K., \& Todman, J. (2008). Theoretical models of culture shock and adaptation in international students in higher education. Studies in Higher Education, 33(1), 63-75. doi:10.1080/03075070701794833

\section{Appendix}

Scales for Challenges and Campus Resources

\begin{tabular}{llrc}
\hline Name & Item & M & SD \\
\hline & English Proficiency & & \\
\hline eng_1 & I find difficulties understanding my professor's accent. & 2.35 & 1.07 \\
eng_2 & My professors have difficulties understanding my accent. & 2.63 & 1.19 \\
eng_3 & I find it difficult to communicate my idea in class & 2.47 & 1.10 \\
eng_4 & I have difficulties writing down my idea & 2.21 & 1.04 \\
eng_5 & My professors teach much material in a single class. & 3.09 & 1.07 \\
eng_6 & My reading speed is slow & 2.89 & 1.28 \\
eng_7 & I have to read my notes over and over before understanding & 2.72 & 1.19 \\
eng_8 & The academic workload often gets me down. & 3.03 & 1.13 \\
eng_9 & My typing speed is slow. * & 2.59 & 1.27
\end{tabular}




\begin{tabular}{|c|c|c|c|}
\hline eng_10 & I have difficulties using Blackboard & 1.88 & 0.89 \\
\hline eng_11 & I have difficulties accessing campus connection & 1.91 & 0.92 \\
\hline eng_12 & I know where to ask for academic help. $\mathrm{R}$ & 2.38 & 1.01 \\
\hline eng_13 & I lack confidence when asking a question in class & 2.73 & 1.26 \\
\hline \multicolumn{2}{|c|}{ Loneliness and Homesickness } & & \\
\hline Lone_1 & I lack companionship. & 2.57 & 1.12 \\
\hline Lone_2 & I have a lot in common with the people around me. $\mathrm{R}$ & 3.04 & 1.14 \\
\hline lone_3 & My interest and ideas are not shared by those around me. & 2.82 & 1.01 \\
\hline lone_4 & I often feel left out. & 2.67 & 1.06 \\
\hline lone_5 & I feel that no one understands me well. & 2.38 & 1.00 \\
\hline lone_6 & I feel isolated from others. & 2.57 & 1.07 \\
\hline lone_7 & I feel shy among the people I interact with. & 2.44 & 1.25 \\
\hline lone_8 & Having close relationships has been difficult to me. & 2.83 & 1.81 \\
\hline lone_9 & I don't have the foodstuff I Like to eat. * & 3.03 & 1.12 \\
\hline lone_10 & I have difficulties taking care of my hair. $*$ & 2.51 & 1.20 \\
\hline lone_11 & I do not feel free to discuss my personal problems with others. & 3.09 & 1.25 \\
\hline \multicolumn{2}{|c|}{ Financial Life } & & \\
\hline fin_1 & It is difficult for me to meet my basic needs. & 2.33 & 0.88 \\
\hline fin_2 & I send money to my family back in my country* & 2.06 & 1.28 \\
\hline fin_3 & I am personally responsible for my needs. $*$ & 3.90 & 1.22 \\
\hline fin_4 & I live a comfortable life with the income I earn. $\mathrm{R}$ & 2.68 & 1.09 \\
\hline fin_5 & I am dependent upon others for my personal needs. $\mathrm{R}^{*}$ & 2.40 & 1.27 \\
\hline fin_6 & I am able to pay all of my bills on time. $\mathrm{R}$ & 2.30 & 1.20 \\
\hline fin_7 & I have always struggled financially. & 2.66 & 1.17 \\
\hline \multicolumn{2}{|c|}{ Help received from different centers. } & & \\
\hline cen_1 & The international center has been of help to me. & 3.36 & 1.12 \\
\hline cen_2 & The writing center has been of help to me. & 2.86 & 1.38 \\
\hline cen_3 & The student success center has been useful to me. & 2.21 & 1.22 \\
\hline cen_4 & I have been to the counseling center for counseling. & 1.89 & 1.21 \\
\hline \multicolumn{2}{|c|}{ Success in your studies } & & \\
\hline succ_1 & How successful do you feel you are in your studies? & 3.96 & 0.80 \\
\hline
\end{tabular}

Note. Participants responded on scale ranging from $1=$ Strongly disagree to $5=$ Strongly agree . "R" indicates that item was reverse coded. * Indicates items that were removed prior to final analyses.

\section{About the Author:}

DELPHINE N. BANJONG is a Graduate Research Assistant in the Department of Teaching and Learning at the University of North Dakota. E-mail: delphine.banjong@my.und.edu 